УДК 624.01

DOI https://doi.org/10.32851/tnv-tech.2021.3.15

\title{
ПРОЄКТУВАННЯ РЕШІТЧАСТОЇ ПОЗАЦЕНТРОВО СТИСНУТОЇ СТАЛЕВОЇ КОЛОНИ ЗА ДОПОМОГОЮ КОМП'ЮТЕРНОÏ ПРОГРАМИ
}

\author{
Чеканович М.Г. - кандидат технічних наук, \\ профессор кафедри будівництва \\ Херсонського державного аграрно-економічного університету \\ ORCID ID: 0000-0002-9110-4109 \\ Янін О.є. - кандидат технічних наук, доцент, \\ доцент кафредри будівництва \\ Херсонського державного аграрно-економічного університету \\ ORCID ID: 0000-0003-0230-8669
}

У статті викладене теоретичне обтрунтування методики використання комп 'ютерного середовища МатһCAD для проєктування решітчастої позачентрово-стиснутої сталевої колони, яка утворюється з двох гілок. Такі колони входять до складу поперечної рами промислової будівлі.

Підкранова гілка розглядається у вигляді нормального двотавра з паралельними гранями полиць. Зовнішня гілка розглядається у вигляді складеного зварного швелера з трьох листів. Гілки з'єднуються решіткою трикутної системи, яка розташована у двох плошинах по зовнішніх гранях гілок. Припускається, шчо решітчаста наскрізна колона працює як шарнірна ферма і в ї̈ гілках виникають поздовжні сили. Проєктування колони виконується з огляду на забезпечення стійкості як колони в циілому, так і окремих ї̈ елементів.

Запропонований алгоритм рішення задачі у комп 'ютерному середовищі MathCAD подiлений на блоки, які призначені для реалізачї певних етапів проєктування. На початковому етапі алгоритму передбачені введення вихідних даних і задання необхідних для розрахунку функиій.

Підпрограма знаходження номеру профільної двотаврової підкранової гілки базується на принципі послідовного перегляду елементів відповідного сортаменту. Перегляд завериується на тому калібрі профілю, за якого буде забезпечена загальна стійкість гілки. Водночас знайдений калібр відповідає мінімальним витратам сталі.

Підпрограма визначення розмірів поперечного перерізу зовнішньої складеної гілки базується на рішенні системи рівнянь загальної $і$ місиевої стійкості за допомогою засобів комп 'ютерного середовища МаthCAD.

Визначення проєктних розмірів колони при фактичних розрахункових поздовжніх силах у гілках виконується методом послідовних наближень, оскільки треба визначити фактичне положення центру ваги перерізу. Цикли послідовних наближень організовані за допомогою оператора while.

Стійкість гілок у площчні поперечної рами будівлі забезпечується відповідним програмним підбором відстані між вузлами решітки наскрізної колони.

Розроблена комп'ютерна методика визначення розмірів поперечного перерізу гілок і розкосів решітчастої позацентрово-стиснутої сталевої колони відкриває можливість швидко та ефективно проєктувати такі конструкиіі згідно з вимогами діючих будівельних норм.

Ключові слова: сталева наскрізна колона, комп 'ютерне середовище, двотавр, швелер, гілка, загальна та місиева стійкість.

Chekanovych M.H., Yanin O.Y. Designing a lattice eccentrically compressed steel column using computer software

The article describes the theoretical substantiation of the methodology for using the MathCAD computer environment for the design of a lattice eccentrically compressed steel column, which consists of two branches. Such columns are part of the transverse frame of an industrial building.

The crane branch is viewed as a normal I-beam with parallel flange edges. The outer branch is considered as a composite welded channel of three sheets. The branches are connected by 
a lattice of a triangular system located in two planes along the outer edges of the branches. It is assumed that the lattice through column operates as a hinged farm and longitudinal forces arise in its branches. The design of the column is carried out on the basis of ensuring the stability of both the column as a whole and its individual elements.

The proposed algorithm for solving the problem in the MathCAD computer environment is divided into blocks that are designed to implement certain design stages. At the initial stage of the algorithm, the input of the initial data and the specification of the functions necessary for the calculation are provided.

The subroutine for finding the number of a profile I-section crane branch is based on the principle of sequential viewing of the elements of the corresponding assortment. The viewing ends at the profile caliber at which the overall stability of the branch will be ensured. At the same time, the found caliber corresponds to the minimum cost of steel.

The subroutine for determining the cross-section dimensions of the external compound branch is based on solving the system of equations for general and local stability using the MathCAD computer environment.

Determination of the design dimensions of the column with the actual design longitudinal forces in the branches is performed by the method of successive approximations, since it is necessary to determine the actual position of the gravity center of the section. Successive approximation cycles are organized using the while operator.

The stability of the branches in the plane of the transverse frame of the building is ensured by the appropriate software selection of the distance between the nodes of the lattice of the through column.

The developed computer technique for determining the dimensions of the crosssection of the branches and braces of a lattice eccentrically compressed steel column opens up the opportunity to design such structures quickly and efficiently in accordance with the requirements of the current building codes.

Key words: steel through column, computer environment, I-beam, channel, branch, general and local stability.

Вступ. На сучасному етапі економічного розвитку України важливим завданням будівельної галузі вважаємо відновлення, реконструкцію не тільки житлових будівників, а й виробничих будівель і інженерних споруд, де проблема проєктування решітчастої позацентрово-стиснутої сталевої колони за допомогою комп'ютерної програми з огляду на забезпечення загальної та місцевої стійкості $\epsilon$ актуальною.

Аналіз останніх досліджень і публікацій. Відомо, що стержень наскрізних решітчастих сталевих колон утворюється з двох гілок, які з'єднуються між собою за допомогою елементів решітки (рис. 1). Така колона входить до складу поперечної рами промислової будівлі [1-3].

Підкранова гілка (гілка № 1) часто виконується у вигляді нормального двотавра з паралельними гранями полиць.

Зовнішня гілка (гілка № 2), як правило, являє собою складений зварний швелер 3 трьох листів.

Гілки з'єднуються решіткою трикутної системи, яка розташована у двох площинах по зовнішніх гранях гілок. Площина згину, що співпадає з площиною поперечної рами будинку, паралельна площинам розташування решітки і перпендикулярна осі $\boldsymbol{X}$.

У колоні, як єдиному наскрізному стержні, у загальному випадку діють поздовжня стискаюча сила $\boldsymbol{N}$ і згинальний момент $\boldsymbol{M}$ відносно осі $\boldsymbol{X}$. Тоді решітчаста наскрізна колона працює як шарнірна ферма і у іiі гілках виникають поздовжні сили.

Розміри поперечного перерізу гілок визначають з огляду на забезпечення [4]:

- загальної стійкості обох гілок у площині та 3 площини поперечної рами будівлі як центрально-стиснутого елементу; 
- загальної стійкості колони в цілому в площині поперечної рами будівлі як єдиного позацентрово-стиснутого наскрізного елементу;

- місцевої стійкості стінки і полиць складеної зварної зовнішньої гілки.

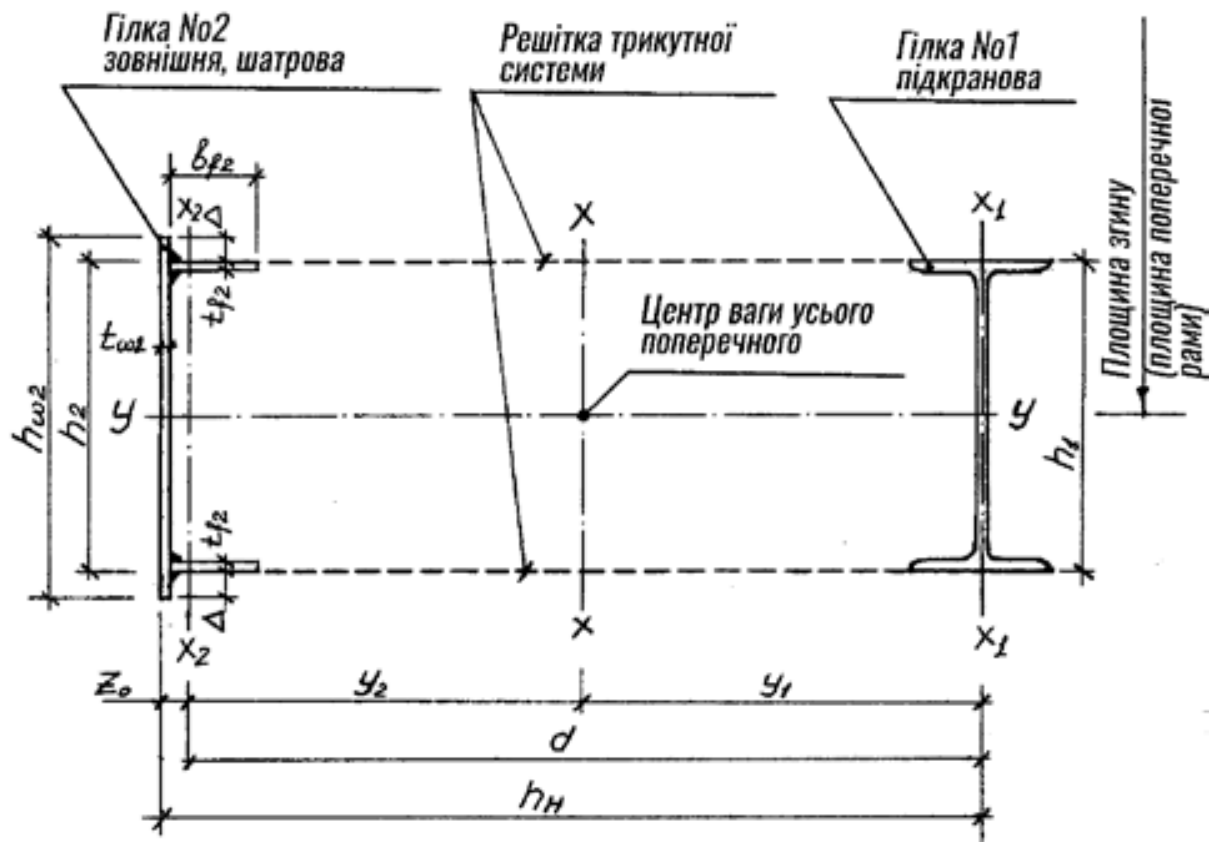

Рис. 1. Поперечний переріз колони

Загальну стійкість центрально-стиснутої $\boldsymbol{i}$-тої гілки перевіряють згідно 3 умовою [4]

$$
\frac{N_{s i}}{\phi_{i} A_{6 i} R_{y} \gamma_{c}} \leq 1,
$$

де $\boldsymbol{N}_{\boldsymbol{s}}$ - максимальна поздовжня стискаюча сила у $\boldsymbol{i}$-тій гілці;

$\varphi_{i}$ - коефіцієнт стійкості гілки;

$\boldsymbol{A}_{\boldsymbol{s i}}$ - площа поперечного перерізу $\boldsymbol{i}$-тої гілки;

$\boldsymbol{R}_{\boldsymbol{y}}$ - розрахунковий опір сталі при розтягуванні, стисканні та згинанні;

$\boldsymbol{\gamma}_{c}-$ коефіцієнт умов роботи колони.

Для підкранової гілки $\boldsymbol{i}=1$, для зовнішньої гілки $\boldsymbol{i}=2$.

Загальну стійкість позацентрово-стиснутої колони у площині поперечної рами як єдиного наскрізного стержня перевіряють згідно з умовою [4]:

$$
\frac{N}{\phi_{e} A R_{y} \gamma_{c}} \leq 1
$$

де $\boldsymbol{N}$ - гранична розрахункова поздовжня стискаюча сила;

$\boldsymbol{\varphi}_{e}$-коефіцієнт стійкості при позацентровому стиску колони;

$\boldsymbol{A}$ - площа поперечного перерізу обох гілок.

Підбір розмірів поперечних перерізів гілок виконують спочатку виходячи із забезпечення їх стійкості з площини поперечної рами будівлі як центрально-стиснутого елементу [5-7]. Для цього необхідно мати максимальні поздовжні стискаючі 
зусилля $\boldsymbol{N}_{\text {вi }}$ у гілках. Вони визначаються положенням центру ваги всього поперечного перерізу колони і розраховуються за формулами:

- для підкранової гілки

$$
N_{61}=N_{1} \frac{y_{2}}{h_{0}}+\frac{M_{1}}{h_{0}}
$$

- для зовнішньої гілки

$$
N_{62}=N_{2} \frac{y_{1}}{h_{0}}+\frac{M_{2}}{h_{0}}
$$

де $N_{1}$ і $\boldsymbol{M}_{1}$ - граничні розрахункові поздовжня сила і згинальний момент у стержні колони як єдиного елементу від розрахункового сполучення навантажень для підкранової гілки;

$\boldsymbol{N}_{2}$ і $\boldsymbol{M}_{2}-$ те ж для зовнішньої гілки;

$\boldsymbol{y}_{1}$ i $\boldsymbol{y}_{2}-$ відстані від центру ваги перерізу колони до центрів ваги перерізів гілок (див. рис. 1);

$\boldsymbol{h}_{\boldsymbol{0}}-$ відстань між центрами ваги гілок.

Розміри $\boldsymbol{y}_{1}$ i $\boldsymbol{y}_{2}$ визначаються площами поперечних перерізів гілок і відповідно розраховуються за формулами

$$
\begin{gathered}
y_{1}=\frac{A_{62} h_{0}}{A_{61}+A_{62}} ; \\
y_{2}=h_{0}-y_{1} .
\end{gathered}
$$

Для визначення розмірів $\boldsymbol{y}_{1}$ i $\boldsymbol{y}_{2}$ необхідно мати розміри поперечних перерізів гілок. Але вони є невідомими. 3 цього випливає, що точне значення поздовжнього зусилля $\boldsymbol{N}_{\boldsymbol{s}} \epsilon$ невідомим, і визначити розміри перерізів обох гілок на підставі умови (1) неможливо.

Традиційно задачу проєктування вирішують шляхом послідовних наближень у наступному порядку [8-11]:

1) приймають у першому наближенні

$$
\begin{gathered}
y_{i} \approx(0,45-0,55) h_{0} ; \\
y_{2} \approx(0,55-0,45) h_{0} ; \\
h_{0} \approx h_{\mu} ;
\end{gathered}
$$
i (4);

2) визначають розрахункові граничні зусилля $\boldsymbol{N}_{\boldsymbol{~}}$ і $\boldsymbol{N}_{62}$ згідно з формулами (3)

3) виконують підбір розмірів перерізів гілок і знаходять $\boldsymbol{A}_{\boldsymbol{~} \boldsymbol{I}}$ i $\boldsymbol{A}_{\boldsymbol{k} 2}$;

4) згідно $з$ формулами (5) i (6) розраховують $\boldsymbol{y}_{1}$ і $\boldsymbol{y}_{2}$;

5) згідно з формулами (3) і (4) обчислюють уточнені розрахункові граничні зусилля $N_{61}$ i $N_{62}$;

6) перевіряють стійкість обох гілок з площини поперечної рами згідно з умовою (1).

У випадках, коли стійкість буде не забезпеченою або забезпеченою з великим запасом, треба виконувати наступний цикл наближення при знайдених параметрах $y_{1}, y_{2}, N_{61}$ і $N_{62}$, починаючи 3 поз. 3 .

Відповідно до традиційного підходу, після підбору перерізів гілок визначають перерізи елементів решітки. Відстань між вузлами знаходять таким чином, щоб була забезпечена стійкість гілок у площині поперечної рами. Потім перевіряють загальну стійкість колони у площині поперечної рами як наскрізного 
позацентрово стиснутого елементу. При необхідності коректують розміри перерізів гілок [1-3].

Постановка проблеми. Описаний шлях послідовних наближень $є$ досить трудомістким і не дає можливості отримати точне рішення задачі. Тому підбір розмірів поперечних перерізів гілок, зважаючи на забезпечення їх загальної стійкості з площини поперечної рами, доцільно виконувати за допомогою комп'ютерної програми. Це дозволить автоматизувати процес проєктування та скоротити час на розрахунки.

Мета дослідження - розробка методики визначення розмірів поперечного перерізу гілок і розкосів решітчастої позацентрово-стиснутої сталевої колони за допомогою комп'ютерної програми згідно з вимогами будівельних норм при врахуванні специфіки виготовлення і монтажу таких колон.

Виклад основного матеріалу дослідження. Для підбору розмірів поперечних перерізів гілок колони на підставі забезпечення вказаних вище нормативних вимог пропонується реалізовувати алгоритм у комп'ютерному середовищі $M a t h C A D$. Цей алгоритм поділений на блоки, які призначені для реалізації певних етапів проєктування.

У блоку № 1 виконується введення вихідних даних для подальших розрахунків.

У блоку № 2 задаються функції:

- коефіцієнту стійкості колони ф;

- гнучкості полиць і стінки зовнішньої гілки (відповідно $\lambda_{\omega 2}\left(\lambda_{u s L}, \boldsymbol{R}_{y}\right)$ і $\left.\lambda_{f 2}\left(\lambda_{u s L}, \boldsymbol{R}_{y}\right)\right)$.

Тут $\lambda_{u s L}-$ умовна гнучкість гілки.

Гнучкості полиць і стінки можуть дорівнювати граничним величинам.

Блок № 3 являє собою підпрограму знаходження номеру профільної двотаврової підкранової гілки, з огляду на умову ії загальної стійкості з площини поперечної рами як центрально-стиснутого стержня при відомій поздовжній силі у гілці $\boldsymbol{N}_{s}$ і розрахунковому опорі сталі при розтягуванні, стисканні та згинанні $\boldsymbol{R}_{v}$. Цій гілці відповідає індекс 1. Підпрограма задається як функція виду $\boldsymbol{N U} \boldsymbol{M}\left(\boldsymbol{N}_{\boldsymbol{b}}, \boldsymbol{R}\right)$. Номер профілю визначається згідно із сортаментом профільної сталі. Кожний іiі рядок відповідає одному калібру профілю. Він містить необхідні геометричні характеристики і параметри:

- висоту поперечного перерізу гілки $\boldsymbol{h}=\boldsymbol{h}_{\boldsymbol{l}}$;

- площу поперечного перерізу гілки $\boldsymbol{A}$;

- радіус інерції поперечного перерізу гілки $\boldsymbol{i}_{\boldsymbol{y}}$ відносно осі, що паралельна обом полицям (на рис. 1 вісь $\boldsymbol{y}$-y).

Рядки розташовані у порядку збільшення площі поперечного перерізу двотавру. Програмним шляхом реалізується послідовний розгляд рядків зверху вниз. При цьому для кожного рядка перевіряється загальна стійкість підкранової гілки 3 площини поперечної рами будівлі. Розгляд завершується на тому рядку, для якого стійкість гілки з площини поперечної рами буде забезпечена. Номер цього рядка позначений літерою «К». Такий підхід дозволяє знайти калібр профілю з мінімальною площею перерізу, для якого забезпечена стійкість підкранової гілки у вказаному напрямку.

Блок № 4 являє собою підпрограму визначення розмірів поперечного перерізу зовнішньої гілки $\boldsymbol{b}_{f 2}, \boldsymbol{t}_{f 2}$ і $\boldsymbol{t}_{\boldsymbol{\omega} 2}$ (див. рис. 1) за умови заданих розмірів $\boldsymbol{h}_{\boldsymbol{\omega} 2}$ i $\boldsymbol{h}_{\boldsymbol{2}}$ у напрямку з площини рами будівлі, а також за певного розрахункового поздовжнього зусилля у гілці $\boldsymbol{N}_{a 2}$. Цій гілці в такому алгоритмі відповідає індекс 2 . Розміри поперечного перерізу гілки визначаються на підставі забезпечення загальної 
стійкості з площини поперечної рами, а також рівності гнучкості полиць і стінки визначеним у блоку № 2 значенням. Для цього вирішується наведена нижче система:

$$
\begin{gathered}
\frac{N_{s 2}}{\phi_{y 2} A_{62} R_{y 2} \gamma_{c}}=1 ; \\
\frac{h_{2}-2 t_{f 2}}{t_{\omega 2}}=\lambda_{\omega 2}\left(\lambda_{u s l 2}, R_{y 2}\right) ; \\
\frac{b_{f 2}}{t_{f 2}}=\lambda_{f 2}\left(\lambda_{u s l 2}, R_{y 2}\right) .
\end{gathered}
$$

Розрахункові параметри $\boldsymbol{\varphi}_{y 2} i \lambda_{u s l 2}$ виражені через такі геометричні характеристики поперечного перерізу зовнішньої гілки:

- радіус інерції відносно осі $Y-\boldsymbol{i}_{\boldsymbol{y} 2}$;

- площу гілки - $\boldsymbol{A}_{62}$;

- момент інерції гілки відносно осі $Y-\boldsymbol{I}_{\boldsymbol{y 2}}$ •

Ці характеристики залежать, зокрема, від розмірів $\boldsymbol{b}_{f 2}, \boldsymbol{t}_{f 2}$ і $\boldsymbol{t}_{\omega 2}$, які необхідно визначити. Тоді, система трьох рівнянь (10-12) містить три невідомі $\left(\boldsymbol{b}_{f 2}, \boldsymbol{t}_{f 2}\right.$ і $\left.\boldsymbol{t}_{\boldsymbol{\omega} 2}\right)$ і має певне рішення, яке виражається в алгоритмі у вигляді функції $\boldsymbol{F}_{1}$. Аргументами цієї функції окрім невідомих $\boldsymbol{b}_{f 2}, \boldsymbol{t}_{f 2}, \boldsymbol{t}_{\omega 2}, \lambda_{y 2}, \lambda_{u s l 2}, \boldsymbol{I}_{\boldsymbol{y} 2}, \boldsymbol{A}_{\boldsymbol{c} 2}, \boldsymbol{i}_{\boldsymbol{y} 2}, \boldsymbol{\varphi}_{y 2}$, будуть також задані параметри $\boldsymbol{h}_{\boldsymbol{\omega} 2}, \boldsymbol{h}_{2}$, і $\boldsymbol{N}_{\boldsymbol{c} 2}$. Тут $\boldsymbol{\lambda}_{\boldsymbol{y} 2}-$ гнучкість зовнішньої гілки 3 площини поперечної рами.

Блок № 5 є підпрограмою знаходження калібру профілю двотаврової прокатної підкранової гілки і розмірів перерізу зовнішньої гілки $\left(\boldsymbol{h}_{\omega 2}, \boldsymbol{h}_{2}, \boldsymbol{b}_{f 2}, \boldsymbol{t}_{f 2}, \boldsymbol{t}_{\boldsymbol{~} 2}\right)$ iз умови забезпечення їх стійкості з площини поперечної рами будівлі як центрально-стиснутих елементів при фактичних розрахункових поздовжніх силах у гілках $\boldsymbol{N}_{\boldsymbol{s}}$ і $\boldsymbol{N}_{\boldsymbol{~} 2}$. Для рішення цієї задачі використовується метод послідовних наближень. При виконанні першого циклу наближення передбачається, що $\boldsymbol{y}_{\boldsymbol{1}}=\mathbf{0 , 5} \boldsymbol{h}_{\boldsymbol{0}}$ i $\boldsymbol{y}_{\mathbf{2}}=\mathbf{0 , 5} \boldsymbol{h}_{\boldsymbol{0}}$ (див. рис. 1). При цих значеннях за формулами (3) і (4) розраховуються поздовжні сили у обох гілках $\boldsymbol{N}_{\boldsymbol{s}}$ i $\boldsymbol{N}_{\boldsymbol{s}}$. Далі, за допомогою підпрограми блоку № 3 при $\boldsymbol{N}_{\boldsymbol{b}}=\boldsymbol{N}_{\boldsymbol{s}}$ знаходиться калібр профільного двотавру підкранової гілки $(\boldsymbol{n m})$ та фіксуються його висота $\boldsymbol{h}_{\boldsymbol{1}}$ і площа поперечного перерізу $\boldsymbol{A}_{\boldsymbol{s}}$. Оскільки $\boldsymbol{h}_{2}=\boldsymbol{h}_{\boldsymbol{l}}$ (див. рис. 1 ), значенню $\boldsymbol{h}_{2}$ присвоюється значення $\boldsymbol{h}_{\boldsymbol{l}}$. Потім розраховується висота стінки зовнішньої гілки $\boldsymbol{h}_{\boldsymbol{\omega}}=\boldsymbol{h}_{\mathbf{2}}+\boldsymbol{\Delta}$. Відстань $\boldsymbol{\Delta}$ приймається таким чином, щоб можна було розмістити зварні шви. Для визначення решти розмірів перерізу зовнішньої гілки $\left(\boldsymbol{b}_{f 2}, \boldsymbol{t}_{\boldsymbol{f 2}}, \boldsymbol{t}_{\boldsymbol{\omega} 2}\right)$ застосовується підпрограма блоку № 4. За допомогою цієї підпрограми обчислюються величини $\boldsymbol{b}_{\boldsymbol{f} 2}, \boldsymbol{t}_{\boldsymbol{f} 2}, \boldsymbol{t}_{\boldsymbol{\prime} 2}$ при знайдених раніше параметрах $\boldsymbol{h}_{\boldsymbol{\omega} 2}, \boldsymbol{h}_{2}$ i $\boldsymbol{N}_{\boldsymbol{\varepsilon}}$. Для цього вводиться одномірний масив-вектор $\boldsymbol{B}$, якому присвоюється значення функції $\boldsymbol{F}_{\boldsymbol{I}}$. Після цього при визначених розмірах поперечних перерізів гілок послідовно розраховуються:

- площа перерізу зовнішньої гілки $\boldsymbol{A}_{\boldsymbol{s}}$;

- відстань від зовнішньої межі зовнішньої гілки до ії центру ваги $\mathbf{z}_{\text {o }}$ (див. рис. 1);

- відстань між осями обох гілок $\boldsymbol{h}_{\boldsymbol{0}}$;

- відстані $\boldsymbol{y}_{1}$ і $\boldsymbol{y}_{2}$

- розрахункові поздовжні сили у гілках $N_{s 1}$ i $N_{62}$. 
Цикли послідовного наближення задаються за допомогою оператора while (поки). Вони будуть виконуватись до тих пір, поки різниця за модулем $\left|\boldsymbol{y}_{1}-\boldsymbol{y}_{01}\right|$ перевищує певну погрішність $\boldsymbol{\delta}$. Тут $\boldsymbol{y}_{01}-$ початковий (попередній) розмір $\boldsymbol{y}_{1}$. Для того, щоб виконати перший вхід у цикли, перед ними розміру $\boldsymbol{y}_{01}$ присвоюється нульове значення. Отже, до входу у цикли різниця $\left|\boldsymbol{y}_{1}-\boldsymbol{y}_{01}\right|=\left|\boldsymbol{0 , 5} \boldsymbol{h}_{\boldsymbol{0}}-\boldsymbol{0}\right|$ перевищує погрішність $\delta$, і первісний вхід до циклів буде реалізований. У всіх циклах перед знаходженням $\boldsymbol{y}_{1}$, попереднє значення цієї величини присвоюється змінній $\boldsymbol{y}_{00}$. Після виконання будь-якого циклу здійснюється розрахунок різниці $\left|\boldsymbol{y}_{1}-\boldsymbol{y}_{01}\right|$. Якщо різниця не менше ніж $\boldsymbol{\delta}$, то починається наступний цикл наближення.

Під час виконання підпрограми блоку № 5 будуть визначені розміри поперечних перерізів обох гілок, при яких вони будуть стійкими у напрямку 3 площини поперечної рами при діючих у них поздовжніх зусиллях і мінімальних витратах матеріалу для підкранової гілки. Ліва і права частини умови загальної стійкості для зовнішньої гілки колони будуть приблизно рівними при достатньо малому значенні параметра $\boldsymbol{\delta}$.

Під час проєктування розміри перерізу зовнішньої гілки $\left(\boldsymbol{b}_{f 2}, \boldsymbol{t}_{f 2}, \boldsymbol{t}_{\boldsymbol{\omega} 2}, \boldsymbol{h}_{\boldsymbol{\omega} 2}\right)$ необхідно прийняти з урахуванням вимог уніфікації, а також технологічних і конструктивних вимог [5]. При остаточно призначених розмірах поперечних перерізів обох гілок у блоку виконуються перевірки їх стійкості 3 площини поперечної рами будівлі. У блоку також передбачені перевірки місцевої стійкості полиць і стінки зовнішньої гілки колони. Для цього порівнюються призначені та граничні гнучкості полиць і стінки.

Гілки будуть стійкими у площині поперечної рами, якщо виконані такі умови:

$$
\begin{aligned}
& \lambda_{x 1} \leq \lambda_{y 1} ; \\
& \lambda_{x 2} \leq \lambda_{y 2},
\end{aligned}
$$

де $\lambda_{x 1}$ і $\lambda_{x 2}$ - відповідно гнучкості підкранової та зовнішньої гілок у площині поперечної рами будівлі при прийнятих розмірах поперечного перерізу;

$\lambda_{y 1}$ i $\lambda_{y 2}-$ фактичні гнучкості гілок з площини поперечної рами будівлі.

У цих перевірках передбачається, що стійкість обох гілок з площини поперечної рами будівлі при значеннях гнучкості $\lambda_{y 1}$ i $\lambda_{y 2}$ забезпечена.

Гнучкості $\lambda_{x 1}$ i $\lambda_{x 2}$ обчислюються за наведеними нижче формулами:

$$
\begin{aligned}
& \lambda_{x 1}=\frac{l_{B}}{i_{x 1}} ; \\
& \lambda_{x 2}=\frac{l_{B}}{i_{x 2}},
\end{aligned}
$$

де $\boldsymbol{l}_{\boldsymbol{s}}$ - відстань між вузлами решітки наскрізної колони;

$\boldsymbol{i}_{x I} \mathrm{i}^{b} \boldsymbol{i}_{x 2}-$ відповідно радіуси інерції перерізів підкранової і зовнішньої гілок у площині поперечної рами будівлі.

3 формул (13) i (14) з урахуванням виразів (15) і (16) будемо мати

$$
\begin{aligned}
& l_{s} \leq \lambda_{y 1} i_{x 1}=l_{b 1} ; \\
& l_{s} \leq \lambda_{y 2} i_{x 2}=l_{\theta 2} .
\end{aligned}
$$

Для того, щоб гілки у площині поперечної рами будівлі були стійкими, розмip $\boldsymbol{l}_{\boldsymbol{s}}$ не повинен перевищувати розрахованих значень $\boldsymbol{l}_{\boldsymbol{\sigma}}$ i $\boldsymbol{l}_{\boldsymbol{g}}$. На підставі цього у блоку № 6 розраховується відстань між вузлами наскрізної колони. Також 
передбачається перевірка стійкості обох гілок у площині поперечної рами при фактичній відстані $\boldsymbol{l}_{\boldsymbol{B}}$.

У блоку № 7 підбираються розкоси решітки колони у вигляді профільного рівнобічного кутика, зважаючи на забезпечення його стійкості у площині найменшої жорсткості як центрально-стиснутого елементу [12].

У блоку № 8 перевіряється загальна стійкість наскрізної колони у площині поперечної рами будівлі як єдиного позацентрово-стиснутого елементу.

\section{Висновки і пропозиції:}

1. Розроблена методика визначення розмірів поперечного перерізу гілок і розкосів решітчастої позацентрово-стиснутої сталевої колони дає можливість швидко та ефективно проєктувати такі конструкції згідно з вимогами діючих будівельних норм.

2. Проєктування наскрізних сталевих колон доцільно виконувати за допомогою комп'ютерної програми. Це дозволяє автоматизувати процес проєктування та скоротити трудомісткість розрахунків.

\section{СПИСОК ВИКОРИСТАНОЇ ЛІТЕРАТУРИ:}

1. Зорин 3.Я. Стальные конструкции. Проектирование на стадии КМД / 3.Я. Зорин, А.А. Новицкий. Киев : Сталь, 2015. 268 с.

2. Мандриков А.П. Примеры расчета металлических конструкций : Учеб. пособие для техникумов. 2-е изд., перераб. и доп. Москва : Стройиздат, 1991. 431 с.

3. Металлические конструкции. Общий курс : Учебник для вузов / Е.И. Беленя, В.А. Балдин, Г.С. Ведеников и др.; Под. общ. ред. Е.И. Беленя. 6-е изд., перераб. и доп. Москва : Стройиздат, 1986. 560 с., ил.

4. ДБН В.2.6-163: 2010. Сталеві конструкції / Норми проєктування, виготовлення і монтажу / Міністерство регіонального розвитку та будівництва України. Київ, 2011. 202 с.

5. ДСТУ Б В.2.6-199-2014. Конструкції сталеві будівельні. Вимоги до виготовлення. Київ : ДП «Укрархбудінформ», 2015. 59 с.

6. Будівельні конструкції, будівлі та споруди третього тисячоліття : Збірник матеріалів Науково-практичної інтернет-конференції. Херсон : ДВНЗ ХДАУ, 2017. 132 с.

7. Збірник наукових праць Українського інституту сталевих конструкцій імені B.M. Шимановського / За заг. ред. заслуженого діяча науки і техніки України, члена-кореспондента НАН України, д.т.н., проф. О.В. Шимановського. Київ : Вид-во «Сталь», 2014. Вип. 14. 152 с.

8. Клименко Ф.С., Барабаш В.М., Стороженко Л.І. Металеві конструкції : Підручник. Львів : Світ, 2002. 312 с.

9. Лугченко О.І. Конспект лекцій з курсів «Будівельні конструкції» та «Будівельні конструкції. Металеві конструкції» / О. І. Лугченко; Харк. нац. ун-т міськ. госп-ва ім. О.М. Бекетова. Харків : ХНУМГ, 2013. 158 с.

10. Марк Лоусон, Артем Билык. Стальные конструкции в архитектуре. Киев : ООО «НПП «Интерсервис», 2014. 135 с.

11. Металлические конструкции: Общий курс : Учебник для студентов высших учебных заведений / Ю.И. Кудишин, Е.И. Беленя, В.С. Игнатьева и др. ; под ред. Ю.И. Кудишина. Москва : Изд. центр «Академия», 2008. 688 с.

12. Металеві конструкції: Загальний курс : Підручник для вищих навчальних закладів. Видання 2-е, перероблене і доповнене / О.О. Нілов, В.О. Пермяков та ін. ; за заг. ред. О.О. Нілова та О.В. Шимановського. Київ : Видавництво «Сталь», 2010.869 c. 


\section{REFERENCES:}

1. Zorin Z.YA. Stal'nyye konstruktsii. Proyektirovaniye na stadii KMD / Z.YA. Zorin, A.A. Novitskiy. - Kiyev: Stal', 2015 - 268 s.

2. Mandrikov A.P. Primery rascheta metallicheskikh konstruktsiy:Ucheb posobiye dlya tekhnikumov. - 2-ye izd., pererab. i dop. - M.: Stroyizdat, 1991. - $431 \mathrm{~s}$.

3. Metallicheskiye konstruktsii. Obshchiy kurs: Uchebnik dlya vuzov / Ye.I. Belenya, V.A. Baldin, G.S. Vedenikov i dr.; Pod. obshch. red. Ye.I. Belenya. 6-ye izd., pererab. i dop. - M.: Stroyizdat, 1986. -560 s., il.

4. DBN V.2.6-163: 2010. Staleví konstruktsíi / Normi proyektuvannya, vigotovlennya í montazhu / Mínísterstvo regíonal'nogo rozvitku ta budívnitstva Ukraíni. - Kiív, 2011. $-202 \mathrm{~s}$.

5. DSTU B V.2.6-199-2014. Konstruktsíi staleví budível'ní. Vimogi do vigotovlennya - K.: DP «Ukrarkhbudínform», 2015. - $59 \mathrm{~s}$.

6. Budível'ní konstruktsíí, budívlí ta sporudi tret'ogo tisyacholíttya»: Zbírnik materíalív Naukovo-praktichnoí ínternet-konferentsíí. - Kherson: DVNZ KHDAU, 2017. - $132 \mathrm{~s}$.

7. Zbírnik naukovikh prats' Ukraíns'kogo ínstitutu stalevikh konstruktsíy ímení V. M. Shimanovs'kogo / Píd zagal'noyu redaktsíêyu zasluzhenogo díyacha nauki í tekhníki Ukraíni, chlena-korespondenta NAN Ukraíni, d.t.n., profesora O. V. Shimanovs'kogo. - K. : Vid-vo «Stal'», 2014. - Vip. 14. - 152 s.

8. Klimenko F.E., Barabash V. M., Storozhenko L.I. Metaleví konstruktsíi:: Pídruchnik. L’vív: Svít, $2002-312$ s.

9. Lugchenko O.Í. Konspekt lektsíy z kursív «Budível'ní konstruktsíi» ta «Budível'ní konstruktsíi. Metaleví konstruktsíi» / O. Í. Lugchenko; Khark. nats. un-t mís’k. gosp-va ím. O.M. Beketova. - KH.: KHNUMG, 2013. - 158 s.

10. Mark Louson, Artem Bilyk. Stal'nyye konstruktsii v arkhitekture. - K. OOO «NPP «Interservis», $2014-135$ s.

11. Metallicheskiye konstruktsii: Obshchiy kurs: Uchebnik dlya studentov vysshikh uchebnykh zavedeniy / YU.I. Kudishin, Ye.I. Belenya, V.S. Ignat'yeva i dr. / pod red. YU.I. Kudishina - M.: Izd. tsentr Akademiya», 2008. - 688 s.

12. Nílov O.O., Permyakov V.O., Shimanovs'kiy O.V., Bílik S.Í., Lavrínenko L.Í., Bêlov Í.D., Volodimirs'kiy V.O. Metaleví konstruktsíi: Zagal'niy kurs: Pídruchnik dlya vishchikh navchal'nikh zakladív. - Vidannya 2-ye, pereroblene í dopovnene / Píd zagal'noyu redaktsíêyu O.O. Nílova ta O.V. Shimanovs'kogo. - K.: Vidavnitstvo «Stal'», 2010. - 869 s. 